\title{
Estimating the commuting cost and commuting time property price gradients ${ }^{1}$
}

\author{
Alex Chan Chung Yi Tse ${ }^{2}$ \\ University of Hong Kong
}

July 2001

\begin{abstract}
In this paper, we estimate the property price gradients in Hong Kong. We distinguish our efforts from previous studies on the estimation of property price gradients by directly measuring the economic distance, i.e. the commuting cost and commuting time, instead of merely the physical distance. Changes in commuting cost exert a statistically significant and fairly pronounced effect on property values. In fact, our estimations suggest that the saving in commuting cost appears to be over-capitalized in property values. The effect of changes in commuting time on property values is either imprecisely estimated or nonmonotonic, however. Nevertheless, the value of time implied by the estimates agrees well with the results reported in the transportation economics literature.
\end{abstract}

\footnotetext{
${ }^{1}$ We wish to thank Alan Siu for some very helpful suggestions, Alice Lee for excellent research assistance, Amy Chan, Holly Lam and Daphne Wong for helping with the data collection and the HIEBS for technical assistance. Tse gratefully acknowledges financial support from a HKU CRGC grant.

${ }^{2}$ Corresponding author. Address: School of Economics and Finance, University of Hong Kong. Pokfulam Road, Hong Kong, email: tsechung@econ.hku.hk.
} 


\section{Introduction}

Anyone who has looked for housing in a big city would know how much property values could vary in relation to locations. There is a simple and intuitive idea dating back more than a century ago by von Thünen (1826) for why locations should matter so much. In a city where jobs are concentrated in one small area, usually known as the central business district, most workers have to commute on a regular basis, for the small area could not possibly house the entire population of the city. Other things equal, the drudgery of commuting would make properties locating closer to the CBD more desirable. In equilibrium, properties locating farther away from the CBD must then be less valuable. The rate at which property values changes in relation to the distance from the CBD is commonly known as the rent gradient. In a model stripped of all secondary elements, the gradient would be a simple function of how commuting cost, broadly defined, increases with distances to the CBD.

Following the modern formulation of the idea by Alonso (1964) and Muth (1969), a large literature has emerged to test the principal prediction that property values should be negatively related to the distance from the CBD and to estimate the magnitudes of the gradients. ${ }^{3}$ The basic approach is to either regress sale price or monthly rent against the property's physical distance to the city's CBD, among a number of controlling variables. In this paper, we shall apply this framework to the Hong Kong owner-occupied housing market. We distinguish our effort from previous studies by directly measuring the economic distance that is the monetary commuting cost and the time spent in commuting, instead of merely approximating the economic distance by the physical distance to be 
covered. $^{4}$ The distinction is crucial for Hong Kong. A host of factors the most important of which is its mountainous terrain make the physical distance often a very poor measure of the economic distance.

We find that the simple correlations between property value and commuting cost and commuting time respectively are indeed negative. And the simple regression of property value against commuting cost and commuting time respectively does yield statistically significant estimates. The negative and statistically significant effects of commuting cost on property value survive in the multiple regression. In fact we find that the saving in commuting cost appears to be over-capitalized in property values. On the other hand, the effect of changes in commuting time on property values is either imprecisely estimated or non-monotonic when commuting cost is also included as an independent variable. Nevertheless, the value of time implied by the estimates agrees well with the results reported in the transportation economics literature.

The next section discusses in more details the von Thünen (1826) model that motivates the estimation. Section 3 discusses our empirical implementation of the model and the construction of the dataset used in the estimations. Section 4 presents the results of the estimations and the last section provides some brief concluding remarks.

\footnotetext{
${ }^{3}$ See Söderberg and Janssen (2001) and the references therein.

${ }^{4}$ Closest to this paper is Coulson and Engle (1987). They estimate how much of the intercity variation in the urban-subsurban property price differential in the U.S. may be attributed to differences in commuting cost across cities.
} 


\section{Model}

The theoretical model that motivates the estimation is a variant of the celebrated von Thünen (1826) model of the determination of urban land rent. There is a monocentric city where all economic activities are located in the central business district. The city is populated by a fixed number of households and the same number of housing units. All housing units are of the same size but may differ in quality. It goes without saying that, other things equal, it tends to take longer and cost more to commute to the CBD for housing units locating farther away from the CBD. But in some cities, other things are rarely equal. Transportation infrastructure may be better developed in some areas than in others, and then the different parts of the city can be lying on vastly uneven terrain. Assuming that the cost and the time of commuting are straightly proportional to the physical distance to be traveled can often be misleading.

Hence, instead of identifying individual housing units by the units' physical distances from the CBD as is customary in previous studies on the estimation of land and property price gradients, we shall differentiate the housing units directly by the commuting costs and time. Specifically, each housing unit may be characterized by its quality $q$, how much it costs $c$ and how long it takes $t$ to commute to the CBD. For simplicity, we assume that all households possess the same utility function that depends on the quality of the housing consumed $q$, leisure $l$ and the consumption of the outside $\operatorname{good} z$ :

$$
u=u(q, l, z) .
$$


The function $u$ is increasing and concave in each of the three arguments. Let the income of the representative household equal $y$, the number of non-working hours equal $h$ and the rent paid equal $d$. Equation (1) may be rewritten as

$$
u=u(q, h-t, y-d-c) .
$$

In equilibrium, all housing units must offer the household the same level of utility.

Hence for any triples of $(q, t, c)$,

$$
u(q, h-t, y-d(q, t, c,)-c)=u^{*}
$$

for some equilibrium level of utility $u^{*}$ and where $d(q, t, c)$ is the equilibrium rent function. Differentiating equation (3) with respect to $q, t$ and $c$ respectively yields

$$
\begin{aligned}
& \frac{\partial d(q, t, c)}{\partial q}=-\frac{u_{1}}{u_{3}}>0, \\
& \frac{\partial d(q, t, c)}{\partial t}=-\frac{u_{2}}{u_{3}}<0, \\
& \frac{\partial d(q, t, c)}{\partial c}=-1<0
\end{aligned}
$$

where $u_{\mathrm{i}}$ denotes the partial derivative of $u$ with respect to the $i^{\text {th }}$ argument. And so the rent commanded by a housing unit should be increasing in its quality and decreasing in the commuting time and cost.

From the last line of (4), we have the value of the property going down one for one when the commuting cost increases. In general, the slope needs not equal -1 exactly, but would depend on the size of the household, the number of commuting trips to be made in each period of time, whether we measure property values by monthly rents or by sale prices and the discount rate if property values are measured by sale prices. 
Nonetheless, these considerations do not alter the basic conclusion that property values should be linearly and negatively related to the cost of commuting. In the estimations to follow, we shall let the data determine the actual slope of the presumably linear relationship and then examine whether the estimates are plausible.

Without further restrictions on the functional form of the utility function and perhaps more importantly, specific assumptions pertaining to the distribution of the triple $(q, t, c)$ among the population of housing units in the city, theory does not impose any specific restrictions on the curvatures of the relationships between property values on the one hand, and commuting time and housing qualities on the other hand. ${ }^{5}$ Most previous studies on estimating the property price and rental gradients assume a semi-log specification in which the dependent variable property value is entered in log but the physical distance from the CBD, among other independent variables, is entered in level. When the independent variable is the physical distance from the CBD, a semi-log specification could well be appropriate. For presumably the physical distance proxies for (1) the monetary commuting cost whose relationship with the physical distance to be traveled needs not be linear if there are fixed costs involved, and (2) the time cost of commuting which can certainly affect property values in a highly non-linear manner.

In the present study, we shall regress property value directly against monetary commuting cost, among other variables. The semi-log specification is thus not quite appropriate in our setting since the property value-monetary commuting cost relationship should be a linear relationship. This consideration suggests that the dependent variable

\footnotetext{
${ }^{5}$ Rosen (1974) and Palmquist (1979) argued early on that the functional form of a Hedonic price function cannot be determined unless the attributes in the Hedonic price function can be repackaged in any way as desired by the consumers.
} 
property value as well as the independent variable commuting cost should be entered in

levels. ${ }^{6}$ On the other hand, we do not wish to constrain the relationships between

property value and commuting time and housing quality respectively to be linear. To

allow for the possible non-linearity then, these variables would be entered in levels and in squares.

\section{Data and the empirical implementation of the model}

Hong Kong has a total land mass equal to 1098 sq. km., divided into 3 major

areas: Hong Kong Island, Kowloon and the New Territories. ${ }^{7}$ As in any large

metropolitan areas, in Hong Kong, commercial activities are scattered throughout the

entire city. Nevertheless, Hong Kong does have a distinctive CBD called the Central

district, devoted primarily to banking, finance and commerce. The Central district is on

the northwestern shore of Hong Kong Island and is one part of the Central and Western

district which is an area of 12.34 sq. km., taking up approximately $1 \%$ of the total land

area in Hong Kong and houses $4 \%$ of the population of Hong Kong. ${ }^{8}$

Of course, not everyone in Hong Kong commute to the Central district. Still,

many do so. And among those who don't, many commute to areas immediately adjacent

\footnotetext{
${ }^{6}$ That property value and commuting cost should be linearly related does not actually preclude entering property value in $\log$ in the regression. If property value is entered in log, we may enter commuting cost in $\log$ and in the square of $\log$, or in level and in the square of level to approximate the underlying linear relationship. It turns out the data fit the model better if property value is indeed entered in log . Our choice of entering property value in level is in the spirit of Cassel and Mendelsohn (1985) who argue that the ease of interpretating the estimates should take precedence over the fit of the data to the model.

${ }^{7}$ Urban Hong Kong is made up of the northern shore of Hong Kong Island and the entire Kowloon Peninsula, while the New Territories is to the north of Kowloon, spanning the area separating urban Hong Kong and mainland China. There are also some 200 outlying islands in Hong Kong and for administrative purpose the outlying islands are included as part of the New Territories.

${ }^{8}$ Sources: Hong Kong Monthly Digest of Statistics, June 2001.
} 
to the Central district. Hence, despite the fact that the assumption of monocentricity is not literally valid, it should still be a useful working assumption.

The distinction that it may not be the physical distance as much as the economic one that influence property values is particularly relevant for Hong Kong. For in the older urban areas, the street grids are seldom lined up at right angles. Besides, much as in San Francesco and in fact to a far greater extent, urban Hong Kong is built on land gradients that rise gradually above the sea level, with differences in altitudes between the lowest and the highest points up to 150 meters. Besides, virtually all of the more recently developed residential areas in Hong Kong are physically separated from the older urban Hong Kong by mountainous terrain of considerable areas. Altogether then, the physical distance from the CBD is often a very poor measure of the economic distance.

Therefore, it would be imperative to use direct economic measures that are the cost and the time to cover the physical distance to be traveled in the analysis.

The major difficulty with using commuting costs and time to measure property values is to decide on the appropriate modes of transportation. There is a straightforward answer for Hong Kong though. Despite having a level of income comparable to many rich countries, private motor vehicle ownership in Hong Kong is at a relatively low level for a variety of reasons, which include a severe lack of parking space in the urban area and high gasoline taxes and import duties on motor vehicles of all kinds. ${ }^{9}$ On the other hand, Hong Kong is served by a very well developed public transportation network that is made up of two urban railways, three franchise bus companies, as well as a host of other smaller players. It would not be far from 100 percent accurate to assume that all

\footnotetext{
${ }^{9}$ There are merely 49 private motor vehicles licensed per 1000 people in 2000 . (Sources: data released by the Hong Kong Transport Department)
} 
commuting is by public transportation since practically everybody in fact commutes to work and school by public transportation.

One may reach the Central district from many places in Hong Kong by more than one forms of public transportation. In constructing our measures of commuting cost and commuting time, we assume that the household would first choose a direct route if available, i.e. the public transportation which would take the commuter from his place of residence directly to the Central district. If the commuter can travel directly to the Central district by more than one forms of public transportation, we would then assume that he would choose the railway over city buses as the former is typically far less time consuming and not much more expensive. However, there are quite many places that are not served by any direct public transportation to the Central district. In this case, we assume that the household would first take the connecting city bus to the nearest railway station and then commute to the Central district by railway. The total time and cost of traveling are then gathered from the schedules provided by the two urban railway companies and the three franchise bus companies.

There are two exceptions to the rules described above. First for housing units locating within a 10 minute walking distance to the Central district, we assume no commuting is necessary and code the commuting cost to be 0 and the time to equal 10 minutes. Second, for housing units locating on the outlying islands, we take that commuting is by ferry, which is in fact the only form of commuting possible.

Inevitably, in our data collection efforts, there were human judgments involved in picking the routes and the forms of public transportation which the commuters may choose for many places. However imperfect they may be, our cost and time measures 
should be superior to merely measuring physical distances. That should be the case since the resulting estimates could be given much more intuitive interpretations, in addition to the benefits of directly measuring economic distances.

Virtually all housing units in Hong Kong are apartments in high-rise residential buildings. ${ }^{10}$ Within a single building or a single housing estate which is a collection of residential buildings that share some common facilities, property values can vary up to 30 percent, depending on the floor, whether the apartment commands a sea view and the tenable condition of the apartment. Unfortunately, we do not have access to information that may help control for quality differences among apartment units within a single building or within a housing estate.

In Hong Kong and possibly in many other places as well, the monthly rent, but not the sale price, depends importantly on the tenable condition of an apartment. That is the case since for the lack of property rights, tenants seldom invest to any significant extent on renovating and improving the tenable condition of a rented apartment. Whereas buyers quite often do. And hence the exact tenable condition of the apartment would be of much greater concern to tenants but not to owner-occupiers. To minimize the effect of the difference in tenable conditions, we shall then measure property values by sale prices instead of by monthly rents.

The other factors such as the floor where the apartment is located and whether the property commands an sea view do lead to considerable variations in sale prices as well as variations in monthly rents within a single building or housing estate. Our solution to the problem is to use the mean sale price of all apartments in the building or the housing

\footnotetext{
${ }^{10}$ There is a negligible number of townhouses while only the few very much families in Hong Kong live in single family home.
} 
estate as the property value to average out any within building/housing estate quality differences which we cannot control for.

Specifically, we pick a random sample of 406 buildings/housing estates ${ }^{11}$ that recorded any sales and purchases within the first 6 months of $2000 .^{12}$ We then use the average sale price/sq.ft. of the apartments within each of these building/housing estates as the dependent variable in the estimation. ${ }^{13}$ The transaction data are collected from the website of Centaline Property Agency, the largest local realtor. For each building/housing estate in the sample, we follow the rules described previously to impute the commuting cost and time to be used as the independent variables. To control for the quality of the entire building/housing estate, we also include as an independent variable the age of the building/housing estate.

Properties on Hong Kong Island tend to be more expensive, followed by properties in Kowloon and then the New Territories. Because of the physical proximity to the Central district, there is usually least traveling for commuters living on Hong Kong Island, followed by commuters living in Kowloon, whereas commuters in the New Territories tend to travel the longest distance. It is often thought that one reason for properties on Hong Kong Island, and to a lesser extent in Kowloon as well, to be more valuable is that Hong Kong Island and Kowloon offer better neighborhoods than the New Territories. It is then important not to confound the effects due to the proximity to the Central district with any possible neighborhood effects. To this end, we shall include two area dummy variables in the regression. In light of the discussion in the previous section,

\footnotetext{
${ }_{11}^{11}$ Our sample of buildings/housing estates do happen to scatter throughout Hong Kong.

12 There were 105,260 sale transactions of private residential properties in the first 6 months of 2000 (Source: data released by the Hong Kong Land Registry).

13 The average sale price is the average of anything from 1 up to 30 transactions.
} 
we shall also allow for possible non-linearity by including the squares of commuting time and building age in the regression. To summarize, our basic model is the following:

$$
P=\beta_{0}+\beta_{1} K L N+\beta_{2} N T+\beta_{3} C+\beta_{4} T+\beta_{5} T^{2}+\beta_{6} A+\beta_{7} A^{2}+\varepsilon
$$

for some e $\sim \mathrm{N}\left(0, \sigma^{2}\right)$ and where

$P=$ sale price/sq.ft. of the apartment in HK dollars,

$K L N=$ dummy for apartments in Kowloon,

$N T=$ dummy for apartments in the New Territories,

$C=$ commuting cost in HK dollars,

$T=$ commuting time in minutes,

$A=$ age of the building.

\section{Results}

Table 1 reports the means and variances of the variables in our sample. The average apartment in our sample costs HK\$2968/sq.ft. and is 13.88 years old as of the year 2000. It takes an average of 37.62 minutes to travel to the Central district and costs HK\$12.51 to do so. There are considerable variations in all variables, with the coefficients of variation ranging from 0.37 to 0.61 . Table 2 reports the correlation coefficients. Not surprisingly, the correlation between commuting time and cost is positive and at 0.70 is fairly pronounced. The correlations between building age and commuting cost and commuting time respectively are both negative. This is due to the fact that, as in most established metropolitan areas of the world, in Hong Kong most of the more recent residential developments are located away from the city center. Hence the newer buildings tend to be those that are farther away from the Central district.

More important for our purpose is that property price is indeed negatively correlated respectively with the cost and the time to commute to the Central district and the age of the building, with correlation coefficients lying between -0.26 to -0.44 . We 
depict these relationships graphically in figures $1 \mathrm{a}, 1 \mathrm{~b}$ and $1 \mathrm{c}$ respectively. The solid lines in the figures are the best-fit lines to the data points. In each case, the slope is statistically significant at 1 percent level. ${ }^{14}$

It does not however follow from the negativity of these simple correlations between property price and commuting cost and commuting time that the cost and time gradients are necessarily negative. First, with commuting cost and commuting time so highly correlated, the partial correlations may turn out to be quite different from the simple correlations. Second, as mentioned previously, properties on Hong Kong Island, and to a lesser extent properties in Kowloon, are thought to be more valuable perhaps not because of their proximity to the Central district, but because in increasing order Kowloon and Hong Kong Island offer better neighborhoods. To isolate any such effects, we need to turn to the multiple regression.

Table 3 presents the results of the OLS estimations. There has been considerable skepticism for the existence of negative price gradients in Hong Kong. For a lot of the properties in the older urban areas immediately surrounding the Central district are far from being the more expensive properties in Hong Kong. The first column of table 3, which only includes commuting cost and commuting time as independent variables, partially confirms this view. Only the cost gradient has the right sign and is statistically significant. With a coefficient equal to merely -0.05 and a t-statistics equal to -0.02 , the time gradient is non-existent for all practical purpose. And so it seems, other things equal, properties whose locations requiring less traveling time to the Central district are not systematically more expensive.

\footnotetext{
${ }^{14}$ The absolute values of the t-statistics lie between 5.43 for building age to 9.88 for commuting cost.
} 
However, once we control for the quality of the apartment by including the age of the building in the regression, column (2) of table 3 shows that the absolute magnitudes and the statistical significance of both the cost and time gradients go up considerably, although the time gradient remains not statistically significant. The age of the building is statistically significant and has the right sign as well. There is good reason for the difference in results. The areas immediately adjacent to the Central district are populated to a very large extent by older and less well-maintained buildings. No wonder then there exists no negative time gradient when the only independent variables are commuting cost and time.

In column 3, we include the Kowloon and the New Territories dummies to check whether the negative cost and time gradients survive once we take into account any possible influences on property values stemming from whether the property happens to locate on Hong Kong Island, Kowloon or the New Territories. It turns out that properties in Kowloon and the New Territories are indeed less valuable than properties on Hong Kong Island, even after holding constant the necessary commuting to the Central district. Notwithstanding the fact that the estimates are only statistically significant at 5\% level, the effects are actually quite large. Yet, the magnitudes and the levels of statistical significance of the cost and time gradients are only lowered marginally by the inclusion of the area dummies. We can be assured then that the negative cost and time gradients identified in column (2) are not wholly neighborhood effects. They do seemingly capture effects arising from the economic distance to the CBD. Within Hong Kong Island, Kowloon or the New Territories, properties that require more commuting to the Central district indeed tend to be less valuable. 
Our analysis so far has found a statistically significant commuting cost but not a commuting time gradient. The time gradient does have the expected negative slope but is only very imprecisely estimated. One possibility for the imprecision in the estimation is that the effect may not be linear. The regression in the fourth column checks for possible non-linearity by including square terms for commuting time and building age. The two square terms are both statistically significant at $5 \%$ level and so non-linearity may in fact be important.

The effect of commuting cost remains negative and statistically significant at $1 \%$ level in the revised specification. Furthermore, the magnitude of the coefficient hardly changes from the estimates obtained previously. Figure 2a plots the implied property price gradient with respect to commuting cost. The data points refer to the differences between the actual property prices and the property prices predicted by the regression in column (4), while omitting the variable commuting cost. The smooth curve then refers to how much of the unexplained property price is accounted for by the effect of commuting cost.

The fit in figure 2a turns out to be quite good. Questions remain as to how reasonable is the estimate of the commuting cost gradient? For a household of two commuters, the number of commuting trips to be made each month would be 104 for a 6day workweek. A dollar reduction in commuting cost would thus save the household HK $\$ 104$ a month or HK\$1,248 a year. The rental yield for owner-occupied apartments in Hong Kong was around 4\% in 2000. Thus the dollar reduction in commuting cost should raise the property value by $\operatorname{HK} \$ 31,200$. The estimate in column (4) is such that a dollar reduction in commuting cost would raise the property value by HK $\$ 95.57 /$ sq.ft. With the 
typical apartment occupied by a household of two commuters in Hong Kong around 600 sq.ft., ${ }^{15}$ our estimate implies that the property value would go up by HK\$57,343 for a dollar reduction in commuting cost. Hence at $4 \%$ discount rate, there seems to be some $45 \%$ over-capitalization of the saving in commuting cost. If the saving were to be correctly capitalized, the discount rate would have to lower to around $2.4 \% .{ }^{16}$ In the few years before the 1997-98 property market crash in Hong Kong, rental yields in Hong Kong were indeed merely around 2-3\%. Thus if the price adjustment in the wake of the market crash in the urban area was somewhat slower than in the outlying areas, our estimates are not at all unreasonable.

For building age, the linear term remains negative and statistically significant while the square term is positive. The overall effect is negative for buildings younger than 37.2 years old and positive thereafter. With the mean building age in our sample 13.88 years old and the maximum age equal to 39 years old, the overall effect is almost always negative. The positive effect that seems to apply to the oldest buildings in the sample is probably due to the inadequacy of the quadratic functional form and should vanish once higher order terms are included. ${ }^{17}$ Within the age range where the effect remains negative, the effect of building age on property value diminishes as the building gets older. There are two possibilities. First, the rate of physical depreciation may slow

\footnotetext{
$1590 \%$ of all newly completed apartments in 2000 are smaller than 750 sq.ft. in size, while $56 \%$ are samller than 450 sq.ft (Source: Hong Kong Monthly Digest of Statistics March 2001). Thus assuming the typical apartment to be 600 sq.ft. in size would not be far from reality.

${ }^{16}$ Coulson and Engle (1987) also find over-capitalization of the saving in commuting cost in their study of estimating the determinants of the urban-suburban property price difference in the U.S. For their estimates to imply a fair capitalization, the discount rate has to be as low as $0.7 \%$. The over-capitalization implied by our estimates is thus far smaller than theirs.

${ }^{17}$ We choose not to include these higher order terms in the analysis because of the complexity involved in interpreting the results. If we restrict the inference to building ages well within the range of the values in the sample, the overall effect will remain negative and the quadratic functional form would not be wholly inappropriate. Problems would only arise if we an attempt an out of sample inference.
} 
down over time. Alternatively, many of the older buildings may have reached $100 \%$ economic depreciation. In this case, the property values would reflect solely the values of the building sites. Any further increases in building age should exert no effect whatsoever on the property values.

As to commuting time, the linear term now turns positive and is statistically significant at $10 \%$ level, while the square term remains negative and is statistically significant at 5\% level. With the absolute magnitude of the coefficient of the linear term exceeding that of the square term, the overall effect implied by the estimates is nonmonotonic, first positive and then eventually turning negative. However, since the linear term is only marginally statistically significant, it is not immediately clear whether it is appropriate to conclude that the commuting time gradient in fact has the inverted-U shape implied by the estimates. If we apply the more stringent requirement of statistical significance at $5 \%$ level, then only the negative square term would remain and the commuting time gradient would be negatively sloped throughout. In light of the fact that the negative commuting time gradients that emerge from the estimations in columns (2) and (3) when only linear terms are included are far from statistically significant, we are inclined to argue that the data do point to a non-monotonic commuting time gradient.

Assuming that the positive coefficient of the linear term does not stem solely from noises, the overall effect of commuting time on property value would be positive for commuting time below 42 minutes and negative thereafter. With the sample mean of commuting time equal to 37.62 minutes and the maximum equal to 80 minutes, the estimated commuting gradient possesses the expected negative slope for more or less the second half of the sample. Figure $2 \mathrm{~b}$ plots the implied property price gradient with 
respect to commuting cost that these estimates imply. Even though the fit is not particularly good, there is a clearly discernible inverted-U pattern in the data.

It is actually not so surprising that our commuting time gradient does not slope downward throughout. Previous studies have often uncovered positively sloped property price gradient when the independent variable is the physical distance to the CBD. Richardson (1977) argues that any property price gradient confounds the usual negative influence of commuting on property values and the positive influence of better environment of locating away from the city center. Urban Hong Kong easily qualifies as one of the most crowded places in the world. Pollution is rampant and public hygiene leaves much to be desired. The positively sloped portion of our commuting time gradient may well be picking up just these effects.

These negative effects arising from locating in close proximity to the city center should eventually die out, however, once we have reached the outskirts of the city center. For apartments locating sufficiently far away from the CBD, the negative effect of commuting should come to dominate. Under this interpretation, the negative portion of our commuting time gradient would then reflect the true commuting time gradient which captures the negative effect of commuting on property values. Take as an example an apartment with a 80 minute commuting distance from the $\mathrm{CBD}$, a 10 minute reduction in commuting would raise the property value by $\mathrm{HK} \$ 16.87 /$ sq.ft according to the estimates in column (4). For a 600 sq.ft. apartment, this comes to an increase in the property value by $\mathrm{HK} \$ 10,127$. Assuming a discount rate of $4 \%$, a household of two commuters and a 6day work week, the value of the 10 minute reduction in commuting would be worth HK $\$ 4$ to each person per commuting trip. The average hourly wage in Hong Kong in 
2000 was $\mathrm{HK} \$ 50 .{ }^{18}$ Our estimates then imply that the value of commuting time is about $48 \%$ of the wage rate, which happen to lie within the $25-50 \%$ range reported by Small (1983) in the transportation economics literature. This coincidence is perhaps surprising for we have taken a very different approach to arrive at the estimate. In any case, the coincidence is surely reassuring evidence that our estimate of the time gradient could not be too far off the mark.

\section{Concluding Remarks}

We have attempted to rationalize the non-monotonic commuting time gradient by resorting to the argument advanced by Richardson (1977) that proximity to the city center might well lower property values because of the deteriorating environment. The same argument should apply equally to the commuting cost gradient. Yet we find a statistically significant and negative commuting cost gradient across different model specifications. In fact the magnitude of the gradient is considerably larger than expected. Besides, the simple correlation between property value and commuting time does have the expected negative sign. And the simple regression of property value against commuting time yields a negative slope the t-statistic of which lies comfortably within the bounds of conventional tests of statistical significance. It is only when commuting cost is also included as an independent variable that the estimates of the commuting time gradient become either imprecise or non-monotonic. Our rationalization along the lines suggested by Richardson (1977) must thus be incomplete. With the small number of

\footnotetext{
18 The average daily wage in Hong Kong in 2000 was HK\$401 (source: Hong Kong Monthly Digest of Statistics, March 2001). Our calculation assumes a 8 hour work day.
} 
variables in our existing dataset, we are not sure how we may pursue the question further. A better answer must await more thorough data collection efforts. 


\section{References}

Alonso, William (1964), Location and land use, Cambridge: Harvard University Press.

Cassel, Eric and Robert Mendelsohn (1985), The choice of functional forms for hedonic price equations: comment, Journal of Urban Economics 18, 135-142.

Coulson, N. Edward and Robert F. Engle (1987), Transportation costs and the rent gradient, Journal of Urban Economics 21, 287-297.

Muth, Richard (1969), Cities and Housing, Chicago: University of Chicago Press.

Palmquist, R.B. (1979), Hedonic price and depreciation indexes for residential housing, Journal of Urban Economics 6, 267-271.

Richardson, H. (1977), On the possibility of positive rent gradients, Journal of Urban Economics 4, 60-68.

Rosen, Sherwin (1974), Hedonic prices and implicit markets: Product differentiation in pure competition, Journal of Political Economy 82, 34-55.

Small, Kenneth (1983), The incidence of congestion tolls on urban highways, Journal of Urban Economics 13, 90-111.

Söderberg, Bo and Christian Janssen (2001), Estaimating Distance Gradients for Apartment Properties, Urban Studies 38, 61-79.

von Thünen, J.H. (1826), Der Isolierte Staat in Beziehung auf Landtschaft und Nationalökonomie. Hamburg (English translation by C.W. Wartenberg von Thünen's Isolated State, Oxford: Pergamon Press, 1966). 
Table 1: Means and Standard Deviations

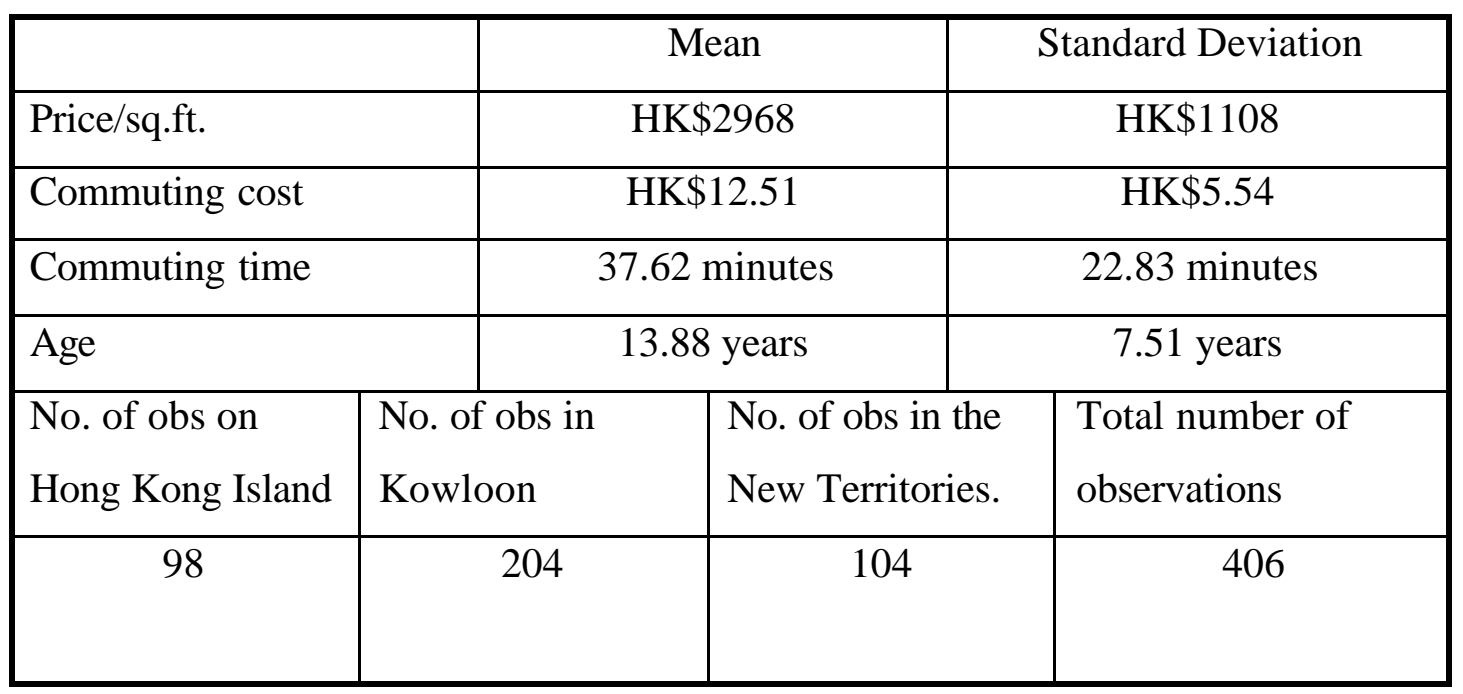

Table 2: Correlation matrix

\begin{tabular}{|l|c|c|c|c|}
\hline & Cost & Time & Age & Log Price/sq.ft. \\
\hline Cost & 1 & 0.70 & -0.36 & -0.44 \\
\hline Time & & 1 & -0.29 & -0.31 \\
\hline Age & & & 1 & -0.26 \\
\hline Log Price/sq.ft. & & & & 1 \\
\hline
\end{tabular}


Table 3: Estimation results

\begin{tabular}{|c|c|c|c|c|}
\hline \multicolumn{5}{|c|}{ dependent variable: price/sq.ft. } \\
\hline & (1) & (2) & (3) & (4) \\
\hline constant & $\begin{array}{c}4071.60 * \\
(33.28)\end{array}$ & $\begin{array}{c}5503.81 * \\
(33.94)\end{array}$ & $\begin{array}{c}5464.31 * \\
(33.07)\end{array}$ & $\begin{array}{c}5583.01 * \\
(24.22)\end{array}$ \\
\hline $\begin{array}{l}\text { commuting } \\
\text { cost }\end{array}$ & $\begin{array}{c}-88.08 * \\
(7.01)\end{array}$ & $\begin{array}{c}118.05^{*} \\
(10.57)\end{array}$ & $\begin{array}{c}-92.09 * \\
(5.47)\end{array}$ & $\begin{array}{c}-95.57^{*} \\
(5.59)\end{array}$ \\
\hline $\begin{array}{l}\text { commuting } \\
\text { time }\end{array}$ & $\begin{array}{l}-0.05 \\
(0.02)\end{array}$ & $\begin{array}{l}-1.78 \\
(0.67)\end{array}$ & $\begin{array}{l}-1.35 \\
(0.50)\end{array}$ & $\begin{array}{l}18.68^{\ddagger} \\
(1.81)\end{array}$ \\
\hline building age & & $\begin{array}{l}-71.48^{*} \\
(11.66)\end{array}$ & $\begin{array}{l}-71.64 * \\
(11.36)\end{array}$ & $\begin{array}{c}-125.70^{*} \\
(6.98)\end{array}$ \\
\hline KLN & & & $\begin{array}{c}-304.2^{\dagger} \\
(2.05)\end{array}$ & $\begin{array}{c}-414.72^{*} \\
(2.80)\end{array}$ \\
\hline NT & & & $\begin{array}{c}-440.68^{\dagger} \\
(2.02)\end{array}$ & $\begin{array}{c}-523.28^{\dagger} \\
(2.42)\end{array}$ \\
\hline $\begin{array}{l}\text { commuting } \\
\text { time square }\end{array}$ & & & & $\begin{array}{l}-0.22^{\dagger} \\
(2.10)\end{array}$ \\
\hline $\begin{array}{l}\text { building age } \\
\text { square }\end{array}$ & & & & $\begin{array}{l}1.69 * \\
(3.20)\end{array}$ \\
\hline $\mathbf{R}^{2}$ & 0.195 & 0.398 & 0.405 & 0.428 \\
\hline Adjusted $\mathbf{R}^{2}$ & 0.191 & 0.394 & 0.398 & 0.418 \\
\hline No. of obs. & 406 & 406 & 406 & 406 \\
\hline
\end{tabular}

Absolute values of t-statistics in parentheses.

* Significant at $1 \%$.

$\dagger$ Significant at $5 \%$.

* Significant at $10 \%$. 
Fig.10: The simple carrelation between property price and commuting cost

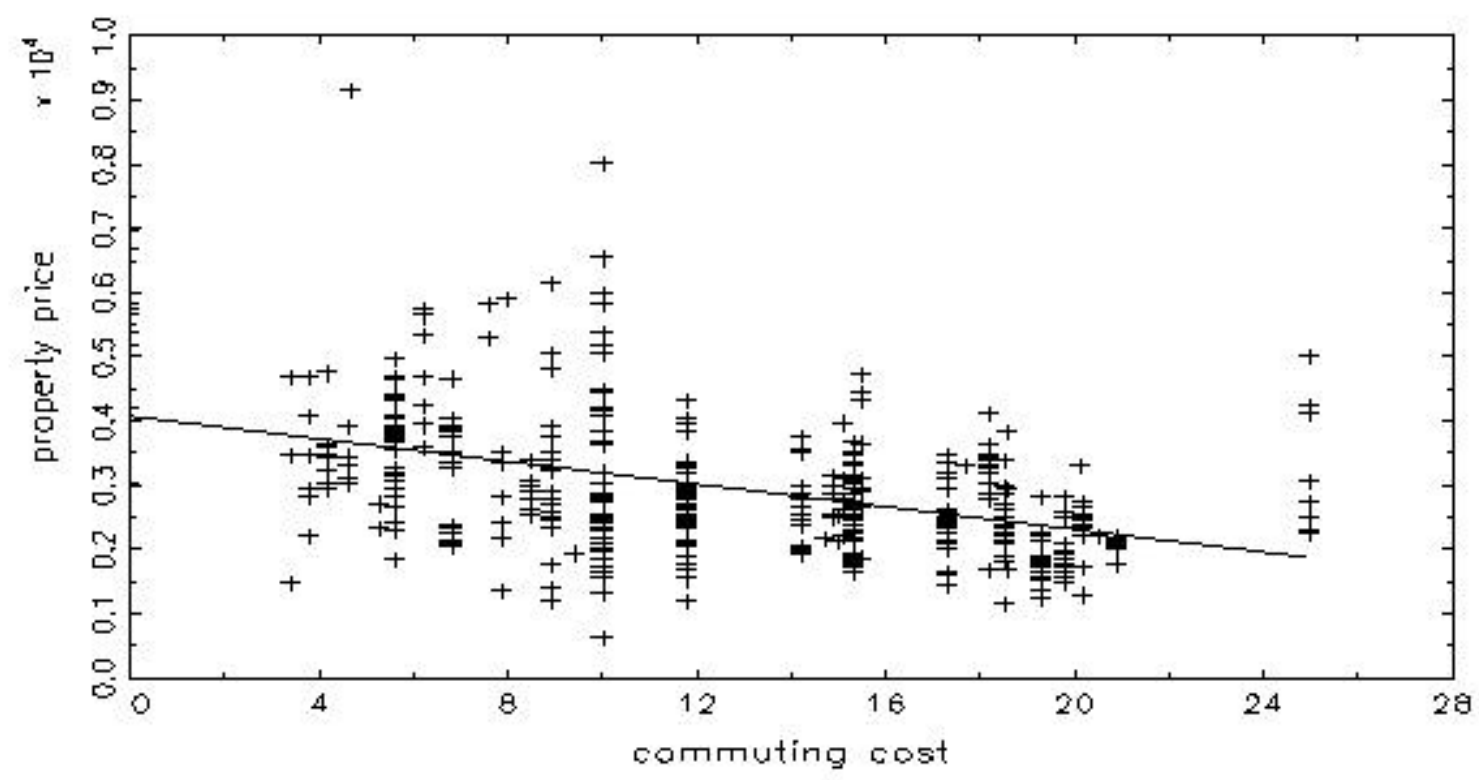

Fig.1b: The simple correlotion between property price and commuting time

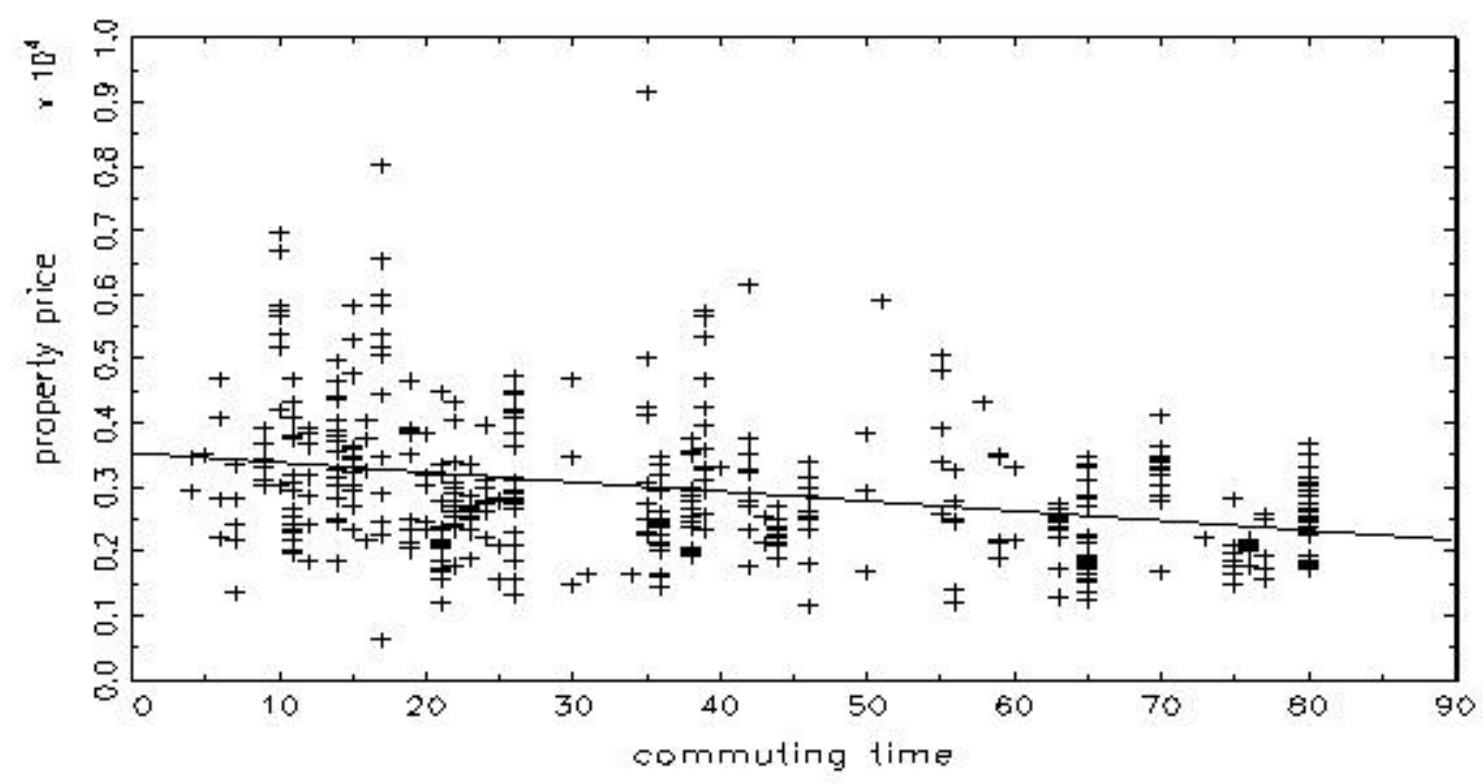


Fig.1s: The simple correlation between property price and building oge

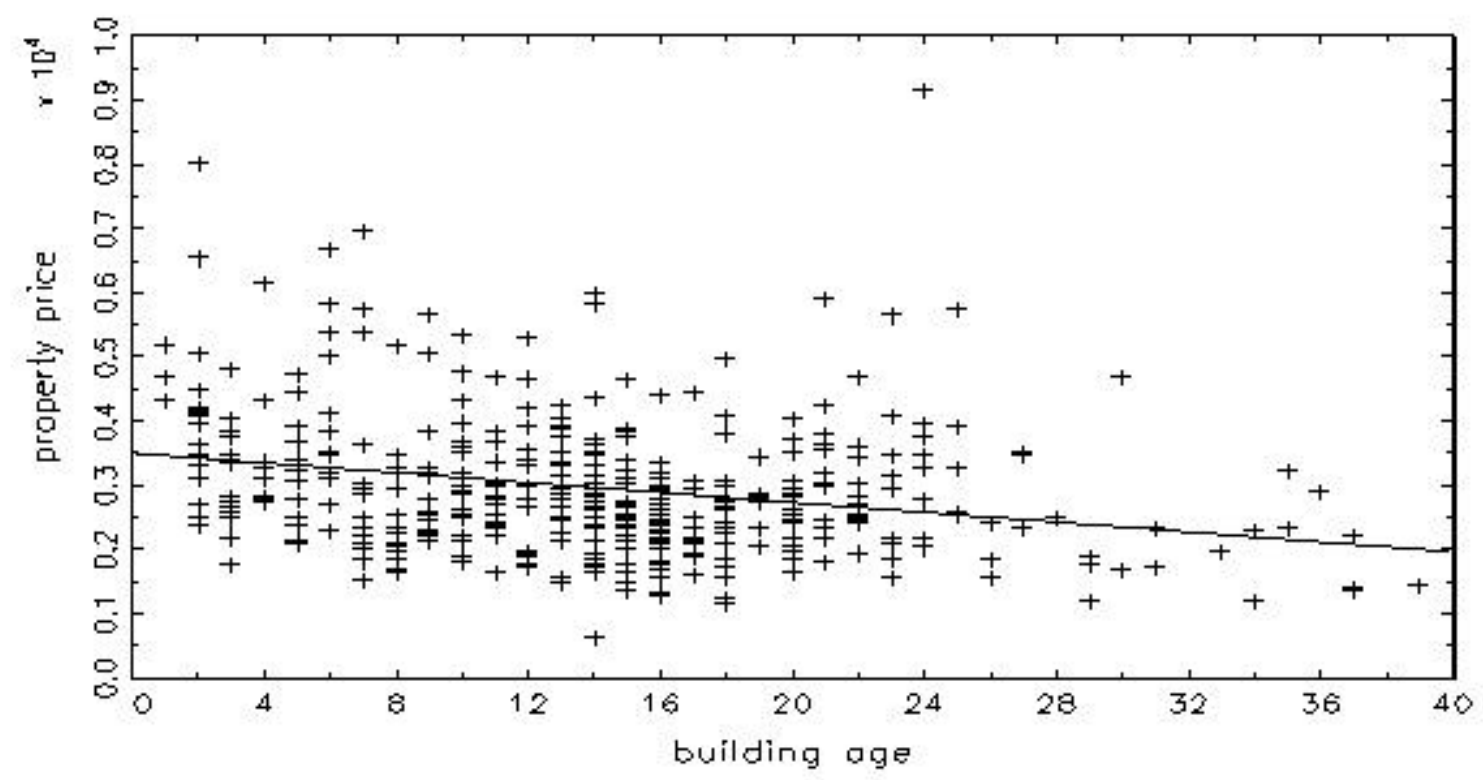


Fig. 2 a: The property price gradient with respect to commuting cost

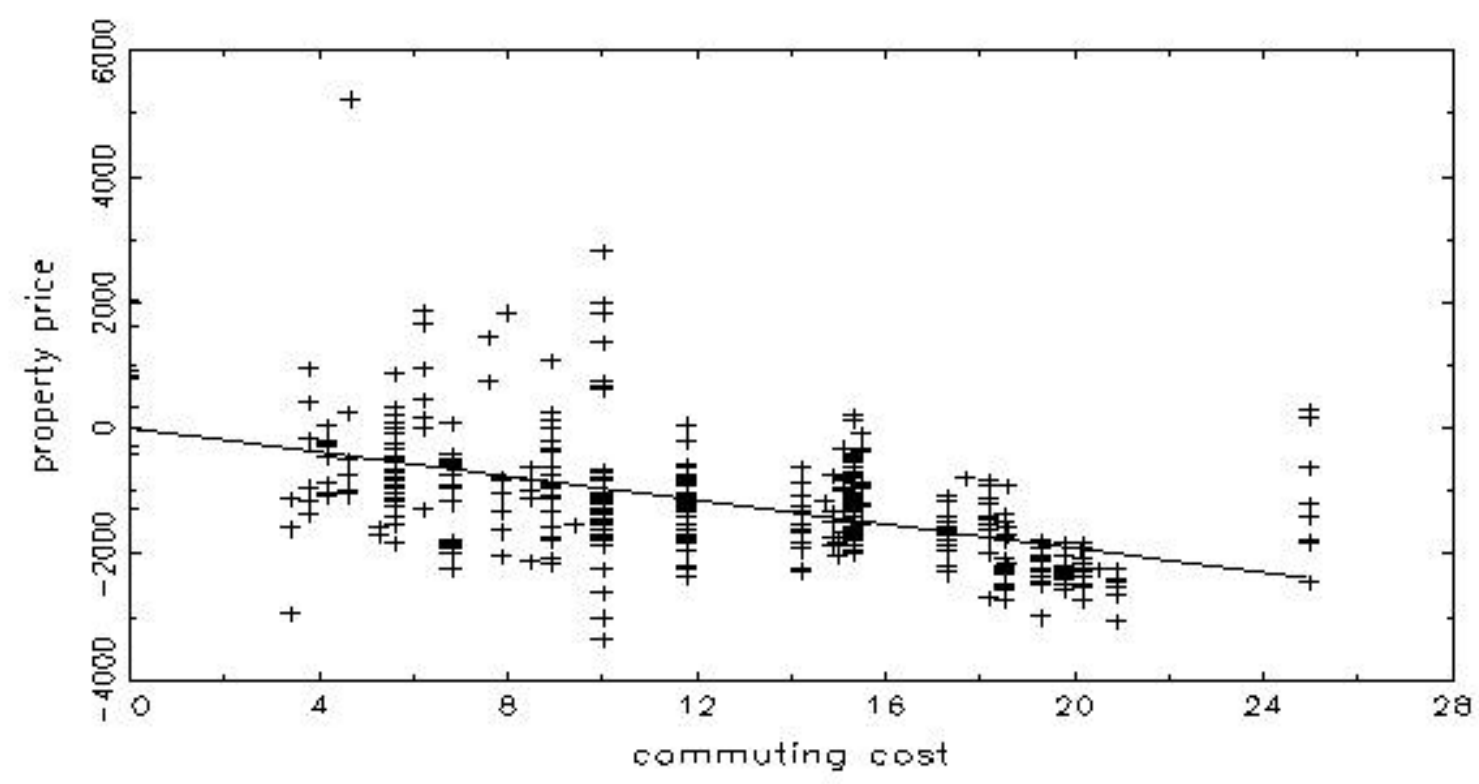

Fig.2b: The property price gradient with respect to commuting time

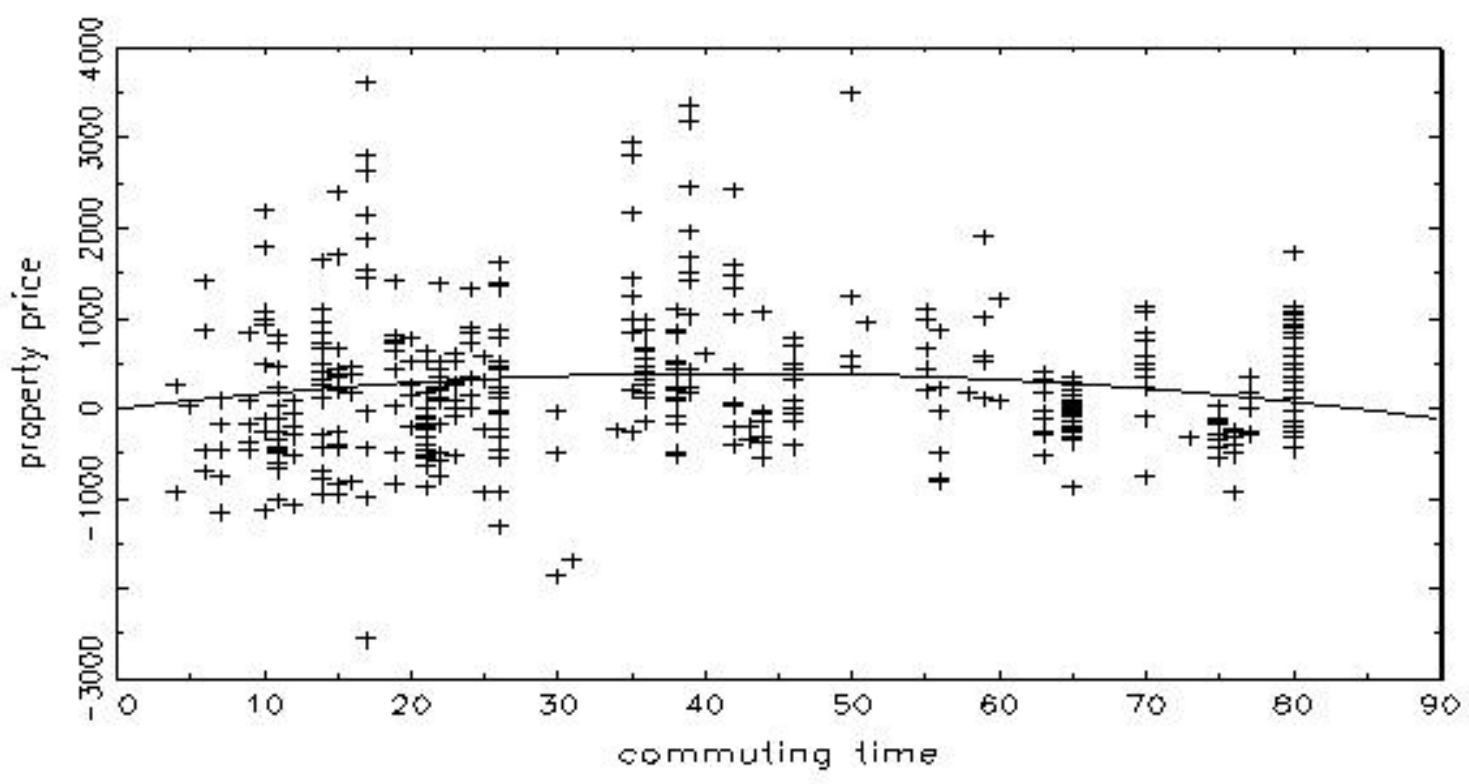

